\title{
INFILTRAÇÃO MARGINAL DE RESINAS COMPOSTAS: MICROPARTÍCULA, MICROHÍBRIDA E NANOHÍBRIDA
}

\author{
MARGINAL LEAKAGE OF COMPOSITE RESINS: MICROPARTICLES, \\ MICROHYBRID AND NANOHYBRID
}

\author{
Osvaldo Benoni da Cunha Nunes \\ Paulo Humaitá de Abreu
}

NANCY Alfieri Nunes

Humberto de Sousa Ramalho
Professor Doutor da Disciplina de Dentística da Faculdade de Odontologia de Lins (FOL/UnimeP)

Professor Doutor da Disciplina de Materiais Dentários da Faculdade de Odontologia de Lins (FOL/UnimeP)

Professora Doutora da Disciplina de Estomatologia da Faculdade de Odontologia de Lins (FOL/UNIMEP)

Acadêmico da Faculdade de Odontologia de Lins (FOL/ UNIMEP)

\section{Resumo}

O objetivo desta pesquisa foi verificar o grau de infiltração marginal em cavidades classe $\mathrm{V}$, vestibular e lingual, em 40 dentes pré-molares humanos extraídos e divididos em quatro grupos, os quais, após ciclagem térmica a $5^{\circ} \mathrm{C} / 55^{\circ} \mathrm{C}$ e corados com o azul de metileno a $2 \%$, foram avaliados sob dois aspectos: 1 - tipos de resina composta: micropartícula (Silux Plus - 3M), microhíbrida ( 250 - 3M) e nanohíbrida (Grandio - VOCO); e 2 - localização da parede cavitária (parede oclusal em esmalte e parede gengival em cemento). Os dados foram mensurados por meio de escores de 0 a 4 e processados estatisticamente pelo teste não paramétrico de Kruskal-Wallis, a fim de demonstrar a resina composta e a parede cavitária que menos permitiu a infiltração do corante. Os três tipos de resina composta - micropartícula, microhíbrida e nanohíbrida - não mostraram diferença estatística significante entre si; a resina nanohíbrida foi a que apresentou os menores escores de infiltração do corante. Também não houve diferença estatística significante entre a parede oclusal em esmalte e gengival em cemento; todavia, a parede oclusal em esmalte foi a que apresentou os menores escores de infiltração do corante.

Palavras-chave: INFILTRAÇÃO MARGINAL - RESINAS COMPOSTAS - NANOPARTÍCULAS.

\section{Abstract}

The objective of this research was to verify the degree of marginal infiltration in class- $V$, vestibular, and lingual cavities in 40 recently-extracted human premolar teeth, divided into four groups, which, after the thermal cycle at $5^{\circ} \mathrm{C} / 55^{\circ} \mathrm{C}$, and stained with $2 \%$ methylene blue, were assessed in two ways: 1 - types of composite resin: microparticles (Silux Plus - 3M), microhybrid (Z 250 - 3M) and nanohybrid (Grandio - VOCO); and 2 - location of the cavity wall (occlusal enamel wall and gingival cement wall). The data were measured through scores of 0 to 4 and statistically analyzed by nonparametric Kruskal-Wallis test in order to demonstrate the composite resin and cavity wall that allowed less dye leakage. The three types of composite resin - microparticles, microhybrid, and nanohybrid - showed no statistically significant difference between them; nanohybrid resin showed the lowest scores of dye penetration. There was no statistically significant difference between the occlusal enamel wall and the gingival cement wall. However, the occlusal enamel wall was the one with the lowest scores of dye penetration. Keyword: MARGINAL INFILTRATION - COMPOSITE RESIN - NANOPARTICLES. 


\section{INTRODUÇÃO}

Com o condicionamento ácido do esmalte, preconizado por Buonocore, ${ }^{1}$ em 1955, e o desenvolvimento das resinas compostas, em 1963, por Bowen, ${ }^{2}$ começou uma nova era na Odontologia Restauradora, pois, a partir daquele momento, o dentista tinha à sua disposição materiais que poderiam ficar aderidos nas cavidades. Bowen ${ }^{2}$ desenvolveu um composto formado pelo Bis-GMA, matriz orgânica com partículas de carga silanizadas que apresentava vantagens, ou seja, peso molecular maior e menor contração de polimerização. Porém, inicialmente, ainda havia muitos problemas como o alto índice de infiltração marginal e a recidiva de cárie, juntamente com pouca estabilidade de cor e resistência mecânica. Com isso, houve um período de descrédito, principalmente quanto ao seu uso em dentes posteriores.

Com o tempo, os materiais restauradores foram sendo aprimorados, e a partir da década de 80 houve um aumento no uso de resinas compostas devido ao surgimento das resinas fotopolimerizáveis e ao melhoramento dos sistemas adesivos.

Atualmente, as resinas compostas, em conjunto com os adesivos dentinários, cimentos de ionômero de vidro modificados por resina e resinas compostas modificadas por poliácidos, ocupam um lugar de destaque na Odontologia, em função das propriedades adesivas que apresentam. Entretanto, se a união ao esmalte é uma prática facilmente obtida e de sucesso, a união à dentina/cemento é mais difícil e de longevidade ainda questionável.

A grande falha das restaurações estéticas continua centrada nas margens cervicais localizadas em dentina ou cemento, em que a adesividade é mais difícil de ser obtida devido à complexa estrutura dentinária e à contínua exsudação de fluidos advindos da polpa.
O vedamento das margens cavitárias localizadas em dentina/cemento utilizando materiais fotoativados também é comprometido pela contração de polimerização que sofrem. A força de união dos sistemas adesivos, cimentos de ionômero de vidro modificados por resinas e resinas compostas alteradas por poliácidos, é insuficiente diante da contração de polimerização, o que provoca um "afastamento" da restauração na região gengival e "gaps" que permitem a penetração de fluidos e bactérias. ${ }^{3}$

Apesar da grande melhoria nas características estruturais das resinas compostas, alguns fatores indesejáveis continuam presentes, como a contração de polimerização e a alteração volumétrica provocadas pelas variações térmicas, podendo levar ao desajuste na interface dente-restauração, com consequente infiltração marginal.

$\mathrm{Na}$ atualidade, as resinas compostas têm sido utilizadas em grande escala nos dentes posteriores, em substituição às restaurações de amálgama de prata. Apesar de elas não terem a longevidade e nem a efetividade seladora do amálgama, seu uso tem sido frequente. Entretanto, são necessárias bases científicas para a correta indicação e uso dessas resinas compostas (micropartícula, microhíbrida e nanopartícula). Portanto, é extremamente importante que se façam testes comprobatórios de sua eficiência, grau de infiltração marginal e longevidade.

Tendo isso em vista, o presente trabalho teve por objetivo avaliar in vitro o grau de infiltração marginal de três tipos de resina composta: micropartícula, microhíbrida e nanohíbrida, testando a influência do tamanho da carga inorgânica delas no vedamento marginal.

\section{REVISÃo DA LiTERATURA}

Segundo a Associação Dental Americana $^{4}$ (ADA), as resinas compostas estão bem indicadas em classes I e II de 
dentes decíduos e de dentes permanentes em cavidades conservadoras. Cavidade conservadora, segundo a mesma entidade americana, é aquela na qual a largura da cavidade na região do istmo não exceda a $1 / 3$ da distância intercuspídica, ou seja, qualquer cavidade que exceda esses limites pode levar a falhas do tratamento restaurador direto com resinas compostas.

Essa indicação precisa para restaurações diretas deverá, ainda, estar associada a uma resina composta que, segundo a $\mathrm{ADA},{ }^{4}$ durante um período de quatro anos de comprovação clínica não ultrapasse $100 \mu \mathrm{m}$ de desgaste nas superfícies oclusais. Atualmente, com o surgimento das resinas compostas híbridas e microhíbridas, esses valores de desgaste oclusal se aproximam dos valores do desgaste apresentado pelo amálgama, que gira em torno de 10-20 $\mu \mathrm{m} /$ ano. Novas resinas compostas de alta densidade denominadas também condensáveis, por exemplo, o Solitaire (Kulzer), Alert (Jeneric/Pentron), SureFil (Dentsply) e, mais recentemente, o Ariston pHc (Vivadent) parecem suplantar, em muito, esses valores, segundo seus fabricantes, as quais surgem como mais uma alternativa às restaurações de amálgama. É importante salientar que a longevidade de uma restauração depende não só do material e de suas qualidades, mas também do profissional que a indica e aplica, e do paciente que fará a manutenção dela mediante hábitos alimentares e higienização corretos.

As resinas compostas atuais ainda são baseadas na formulação de Bowen, ${ }^{2}$ porém com algumas modificações. A matriz resinosa, que é a parte quimicamente ativa com monômeros que vão estabelecer ligações cruzadas no momento da polimerização conferindo resistência ao material, é comumente constituída pelo Bis-GMA (Bisfenol-A glicidil metacrilato) ou UDMA (uretano dimetacrilato). Existem ainda diluentes como o TEG-DMA (Trietileno glicidil dimetacrilato) ou EDMA (Etileno glicol dimetacrilato), que reduzem a viscosidade, entretanto aumentam a contração de polimerização, e mais um inibidor de polimerização para garantir vida útil mais longa, sendo a hidroquinona o mais utilizado. Hoje em dia já existem resinas com outros tipos de matrizes devido à constante busca por parte dos fabricantes por materiais cada vez melhores. À matriz orgânica são incorporadas partículas de carga (porção inorgânica) para melhorar as propriedades físicas do material, possibilitando diminuir a contração de polimerização e aumentar a resistência ao desgaste. São cargas comumentes usadas: quartzo, sílica coloidal, vidro de fluorsilicato de alumínio, além de bário e estrôncio, os quais proporcionam radiopacidade. No entanto, há um limite para essa incorporação de carga, pois ela pode prejudicar a função estética. Para desencadear a reação de polimerização, existem os iniciadores. A amina terciária segmenta o peróxido de benzoíla, dando início ao processo (nas resinas quimicamente ativadas). Já nas resinas fotopolimerizáveis à luz, que tem um comprimento de onda de 470 nanômetros, ativa a canforoquinona (iniciador), gerando a interação reativa com as aminas terciárias.

$\mathrm{Na}$ década de 80, existiam três tipos de tamanho de partícula inorgânica: partícula fina, cujo tamanho variava de 1,0 a 5,0 micrômetros; micropartícula, que oscilava entre 0,02 e $0,07 \mathrm{mi}-$ crômetros; e partícula híbrida, que se situava entre 0,04 e 5,0 micrômetros. Essa variação no tamanho das partículas inorgânicas (carga) conferia diferentes índices nas propriedades das resinas compostas. Sistemas atuais são satifatórios para casos selecionados de classe I e II e utilizam partículas menores que $1 \mu \mathrm{m}$, numa concentração em peso de $75 \%-86 \%$. Desses materiais, os mais populares são Herculite XR, Prisma APH e P-5O (híbridas) e o Heliomolar (micropartícula). A resistência ao desgaste 
é aumentada, introduzindo-se partículas de microenchimento pré-polimerizadas com adesão melhorada à matriz de resina. As resinas de megapartículas incorporam vidro para protegerem-se do desgaste. A partir desses melhoramentos, o desgaste oclusal médio da resina composta posterior teve uma redução acentuada. ${ }^{5}$

Atualmente, as resinas compostas podem ser classificadas quanto ao tamanho das partículas inorgânicas, existindo: (1) macropartículas, que são partículas com tamanho entre 15 e 100 micrômetros, sendo denominadas convencionais; (2) micropartículas, que são partículas com tamanho médio de 0,04 micrômetros; (3) híbridas, que são compostas por macro e micropartículas com tamanho entre 1 e 5 micrômetros; (4) microhíbridas, que são uma combinação entre micropartículas (0,04 micrômetros) e partículas maiores de, no máximo, 2 micrômetros, com tamanho médio de 0,6 e 0,8 micrômetros. ${ }^{6}$

Complementando a classificação das resinas compostas, temos as nanopartículas (nanohíbridas) que, em pesquisa, são partículas virtualmente invisíveis, cujo tamanho $(0,005-0,01 \mu \mathrm{m})$ está abaixo do comprimento de onda de luz visível. $\mathrm{O}$ ajuste perfeito entre essas partículas permite uma concentração em peso de 90\%-95\%, melhorando amplamente suas propriedades físicas. Pesquisas atuais envolvem o uso de partículas pequenas com melhores propriedades de enchimento, partículas radiopacificadoras mais eficientes, monômeros que expandem na fotopolimerização e eficiência de polimerização em qualquer volume. Resinas compostas de nanopartículas são materiais pesquisados atualmente, que diminuem significativamente a contração de polimerização e melhorando a integridade marginal. ${ }^{7}$

Segundo Hinoura et al., ${ }^{8}$ a adaptação marginal é influenciada pelos se- guintes fatores: (1) preparo cavitário; (2) técnica de condicionamento ácido do esmalte; (3) uso do adesivo; (4) técnica de inserção; (5) procedimentos de acabamento; e (6) o próprio material restaurador.

Hansen e Asmussen ${ }^{9}$ estudaram a adaptação marginal de resinas compostas e avaliaram o efeito da utilização de adesivos dentinários e a expansão higroscópica. Os resultados mostraram que nenhum dos adesivos foi capaz de evitar a formação de fendas entre as paredes da cavidade e a restauração, porém os resultados obtidos com a resina de micropartículas foram significantemente melhores do que os obtidos com resinas indicadas para dentes posteriores. Os autores atribuíram os resultados à alta viscosidade das resinas posteriores e ao fato de apresentarem menor conteúdo orgânico e, consequentemente, menor expansão higroscópica.

Segundo Bausch, ${ }^{10}$ em um estudo de tese, a contração de polimerização da resina composta varia em $2 \%$ a $3 \%$ do volume, entretanto os fabricantes esperam que futuramente existam matrizes resinosas com mínima contração de polimerização.

Responsabilizando a contração de polimerização das resinas compostas pela formação precoce de uma fenda na interface dente-restauração, Prati $^{11}$ avaliou a microinfiltração imediata de várias resinas compostas da época, quando utilizadas com sistemas adesivos ou cimento de ionômero de vidro, e observou que as resinas compostas com maior quantidade de carga apresentaram os piores resultados, atribuindo esses valores ao alto módulo de elasticidade desses materiais. $\mathrm{O}$ autor mencionou que o fluxo do material durante a polimerização é uma característica desejada para compensar a contração, acrescentando que resinas compostas mais flexíveis também são mais efetivas em selar as margens das restaurações. Tanto 
módulo de elasticidade como fluxo são dependentes da composição do monômero e da quantidade de partículas de carga.

Prati, ${ }^{12}$ em 1989, realizou uma pesquisa in vitro para avaliar a microinfiltração inicial originada pela formação de fendas em várias resinas compostas utilizadas em cavidades convencionais de classe II (MOD), comparando a influência de sistemas adesivos e de cimentos ionoméricos de vidro. Ressaltou que tal estudo procurava diferir-se dos anteriores, que tinham sido realizados após um período de armazenamento dos corpos de prova imersos em água, possibilitando, assim, a expansão higroscópica da resina composta, com consequente redução das fendas formadas na interface dente-restauração. Foi confirmado que a junção adesiva esmalte-resina composta resistiu aos estímulos de contração de polimerização. Foi demonstrado que a microinfiltração se apresentou em quantidades consideráveis durante o tempo imediatamente após a restauração, especialmente na junção cemento-esmalte. $\mathrm{O}$ tipo de resina composta, e não o agente adesivo, foi o principal fator responsável por essa microinfiltração. Resinas compostas híbridas com maiores quantidades volumétricas de cargas apresentaram maior infiltração marginal na dentina, ao contrário do que foi observado para as resinas de micropartículas.

Em 2000, Suh ${ }^{13}$ citou em seu trabalho que a contração de polimerização é uma propriedade física, em consequência de uma reação química, e é inerente ao material restaurador. Considerou que as resinas compostas apresentam matriz orgânica que contrai $10 \pm 2 \%$ em volume, e carga inorgânica que não contrai. Relatou que, quanto mais carga inorgânica é adicionada ao material, menor será a contração de polimerização resultante da resina composta. Porém, segundo o autor, isso não significa que toda resina com baixa contração de polimerização gere, necessariamente, menos estresse de contração em função do módulo de elasticidade tornar o material mais rígido, podendo sofrer menor deformação plástica durante a fase de contração.

Tessore e Trinchero ${ }^{14}$ afirmaram que, teoricamente, uma resina composta com alta concentração de carga tem uma menor contração de polimerização, mas paradoxalmente ela pode gerar maior estresse por ser menos elástica e possuir menor capacidade de escoamento para compensar a contração do material.

Santos et al. ${ }^{15}$ realizaram uma revisão de literatura em 2002, na qual citaram que a contração de polimerização é um dos fatores que mais contribuem para o insucesso das resinas compostas e que ela é o resultado da movimentação e aproximação dos monômeros entre si durante a formação da cadeia polimérica. Afirmaram que, quanto maior o grau de conversão do monômero, maior é a contração de polimerização e que, nas resinas atuais, o grau de conversão fica em torno de $60 \%$ a $70 \%$, e a contração de polimerização foi reduzida para $1,5 \%$ a 3\%. Relataram que a contração de polimerização é inerente às resinas compostas e irá persistir até que resinas sem contração ou portadoras de monômeros, que sofram expansão durante a reação de polimerização, estejam disponíveis. Concluíram que inúmeros fatores são responsáveis pelo estresse gerado na contração de polimerização, tais como módulo de elasticidade, composição da resina composta, fator de configuração da cavidade e intensidade de luz emitida pelo aparelho fotopolimerizador. Como forma de minimizar essa contração, indicaram o uso de intensidades mais baixas de luz, com o intuito de prolongar a fase pré-gel, e o uso da técnica incremental para reduzir o Fator C. 
Gomes et al. ${ }^{16}$ realizaram uma análise in vitro da microinfiltração marginal em cavidades de classe $\mathrm{V}$, confeccionadas nas faces vestibular e lingual de terceiros molares humanos recém-extraídos, restauradas com resina composta de micropartícula Durafill, utilizando quatro marcas diferentes de sistemas adesivos: Excite (Vivadent), Prime \& Bond NT (Dentsply), Prompt L-Pop (Espe) e One Coat Bond (Coltène). Os dentes foram termociclados e, para a análise da microinfiltração, foram imersos durante duas horas, em solução de nitrato de prata a 50 por cento. Como resultado, obtiveram que todos os sistemas adesivos praticamente evitaram a microinfitração nas margens oclusais. Nas margens cervicais, porém, nenhum deles foi capaz de inibir a microinfiltração.

Ursi e Simone ${ }^{17}$ relataram que, desde o desenvolvimento da técnica do condicionamento ácido do esmalte, ${ }^{1}$ incessantes pesquisas têm surgido no meio odontológico, no intuito de alcançar uma adesão eficaz de materiais restauradores com a estrutura dentinária. Os adesivos dentinários atuais apresentam desempenho mais promissor em relação aos seus antecessores, uma vez que melhores resultados clínicos e laboratoriais têm sido alcançados. Porém, a adesão a dentina continua menos eficaz em relação ao esmalte, principalmente devido à variabilidade química e estrutural que o substrato apresenta. Segundo a grande maioria dos autores pesquisados, cavidades médias ou rasas, circundadas totalmente por esmalte condicionável por ácidos, dispensam a utilização de materiais protetores do complexo dentina-polpa, uma vez que a infiltração marginal nesses casos é praticamente evitada. Todavia, o condicionamento ácido em cavidades profundas ou mesmo sobre exposições pulpares, que tem sido amplamente reportado, está longe de representar um consenso.
Testes de resistência adesiva ao cisalhamento, que no passado eram utilizados como determinantes da capacidade de selamento de um agente, atualmente não apresentam tamanha confiabilidade, pois não existe comprovada relação entre essas características. Além disso, na maioria dos trabalhos pesquisados, os sistemas adesivos dentinários de quarta geração fracassaram em conseguir um selamento hermético da restauração, em cavidades com paredes localizadas em dentina.

Formolo et al. ${ }^{18}$ realizaram um trabalho com o objetivo de comparar a infiltração marginal em cavidades de classe $\mathrm{V}$, restauradas com diferentes materiais. Foram preparadas cavidades nas faces vestibular e lingual, com término cervical em cemento e término oclusal em esmalte, em 25 terceiros molares humanos hígidos. Os espécimes foram aleatoriamente divididos em cinco grupos ( $\mathrm{n}=10$ cavidades) e restaurados com os seguintes materiais: cimento de ionômero de vidro Vidrion R (SS White); cimento de ionômero de vidro modificado por resina Vitremer (3M); compômero Dyract (Dentsply); compômero F2000 (3M); e resina Flow-it (Jeneric/Pentron). Todos os materiais foram empregados de acordo com as recomendações dos fabricantes. Uma unidade fotoativa XL3000 (3M) foi empregada durante o experimento. Após acabamento e polimento, os dentes foram submetidos à termociclagem e imersos em azul de metileno. Depois de seccionados os dentes, a infiltração foi avaliada por três examinadores, com base em escore padronizado. Os dados, quando submetidos à análise estatística, demonstraram não haver diferenças estatisticamente significantes de infiltração em cemento entre os materiais testados $(\mathrm{p}>0,05)$. Em esmalte, o Vidrion $\mathrm{R}$ mostrou maiores valores de infiltração $(\mathrm{p}<0,01)$, quando comparado aos outros grupos, os quais demonstraram 
resultados similares entre si. Os valores de infiltração em cemento foram estatisticamente maiores que aqueles encontrados em esmalte $(\mathrm{p}<0,01)$.

Cavalcanti ${ }^{19}$ avaliou a microinfiltração in vitro nas margens de esmalte e dentina em cavidades classe $V$, preparadas com alta rotação ou laser de Er: YAG e restauradas com os sistemas adesivos Single Bond (3M) ou Clearfil SE Bond (Kuraray). Foram utilizados 36 terceiros molares, humanos, hígidos, nos quais foram confeccionadas cavidades classe $\mathrm{V}$ nas faces vestibular e lingual de cada um deles, totalizando 72 cavidades. Os espécimes foram divididos em quatro grupos iguais, sendo: Grupo 1: preparo com alta rotação + Single Bond; Grupo 2: preparo com alta rotação + Clearfil SE Bond; Grupo 3: preparo com Laser Er: YAG + Single Bonde; Grupo 4: preparo com Laser Er: YAG + Clearfil SE Bond. Para o preparo com laser Er: YAG (KAVO KEY), foram utilizados $300 \mathrm{~mJ}, 4 \mathrm{~Hz}$ de taxa de repetição e densidade de energia de $96,463 \mathrm{~J} / \mathrm{cm}^{2}$. Os espécimes foram restaurados com a resina composta micro-híbrida Filtek $\mathrm{Z}$ 250 - 3M, termociclados (500 ciclos a $5^{\circ} \mathrm{C} / 55^{\circ} \mathrm{C}, 20$ segundos em cada temperatura), imersos em solução de fuccina básica a 0,5 por cento por 24 horas a $37^{\circ} \mathrm{C}$. Os dentes foram seccionados e avaliados por meio de uma lupa estereoscópica por três examinadores, segundo escores de zero a três. Os resultados foram submetidos ao teste estatístico de Mann-Whitney, ao nível de significância de 5\%. Concluiu-se que tanto os sistemas adesivos (Clearfil SE Bond e Single Bond) quanto os preparos com alta rotação e laser de Er: YAG apresentaram comportamentos semelhantes com relação à microinfiltração marginal. As margens em dentina mostraram maior infiltração quando comparadas às margens em esmalte.

Pereira ${ }^{20}$ avaliou a contração de polimerização de quatro resinas compos- tas: Filtek Z 250 - 3M (micro-híbrida), Filtek Supreme 3M (nano-híbrida), Admira - VOCO (ormocer) e Grandio - VOCO (nanohíbrida) utilizando três metodologias diferentes. A primeira foi obtida em uma máquina de ensaios na qual um programa de computador mediu as forças transmitidas pelo material restaurador durante a presa. A segunda metodologia avaliou a contração linear livre da resina em uma matriz de teflon. A terceira metodologia avaliou a contração parede a parede em cavidades cilíndricas de dentina bovina. Os resultados mostraram que não houve diferença estatisticamente significante na magnitude das forças geradas durante a contração de polimerização. Por outro lado, houve diferenças estatisticamente significantes representadas pelas fendas marginais durante a contração linear livre de polimerização entre as quatro resinas, na qual a resina composta microhíbrida Z 250 - 3M apresentou a maior fenda marginal e na resina nano-híbrida Grandio - VOCO verificou-se a menor fenda. No que diz respeito à contração de polimerização parede a parede e respectiva formação de fendas marginais, não houve diferenças estatisticamente significantes entre as quatro resinas compostas analisadas.

Pode-se notar que, nos últimos anos, tem havido uma grande preocupação por parte dos fabricantes de resinas compostas em reduzir a contração de polimerização, utilizando novos recursos como a nanotecnologia ou novos materiais como o Ormocer, conseguindo, assim, uma geração de resinas com melhor comportamento que a maioria das resinas compostas microhíbridas no que diz respeito à contração de polimerização. ${ }^{20}$ Isso poderia sugerir um comportamento clínico melhor da restauração, sobretudo no que se refere à formação de fendas marginais e seu potencial de microinfiltração. 


\section{Materiais e Métodos}

Foram utilizados nesta pesquisa dentes pré-molares humanos extraídos por razões ortodônticas, pré-selecionados e indicados para exodontia no curso de Especialização em Ortodontia, por meio de radiografias panorâmica e cefalométrica, bem como modelo de gesso e traçado ortodôntico, que orientam ou não a necessidade de extração dentária.

Os pacientes, adolescentes de 12 a 15 anos, foram encaminhados, por escrito e por indicação de necessidade de remoção dentária, à Clínica de Cirurgia da Faculdade de Odontologia de Lins (FOL) As extrações foram realizadas gratuitamente, na referida clínica, por acadêmicos do curso de graduação, acompanhados pelo bolsista do curso e sob supervisão direta dos docentes da disciplina. Não houve participação do doador na pesquisa, de tal forma que não existiu risco de danos pessoais. Qualquer outro dano não previsto que ocorreu durante a extração foi de responsabilidade dos docentes da Clínica de Cirurgia da FOL. Não houve necessidade de ressarcimento por parte dos pesquisadores, pois não existiu risco algum para os doadores, visto que o material foi utilizado em pesquisa in vitro. O critério de inclusão dos dentes doados foi o da indicação de extração por necessidade do tratamento ortodôntico dos adolescentes, sendo critério de exclusão os dentes de adolescentes ou adultos fora da faixa etária estabelecida, ou os dentes extraídos por outras razões que não as ortodônticas. Os benefícios esperados não estavam diretamente ligados aos doadores, e sim à escolha de melhores materiais restauradores a serem utilizados na Clínica de Dentística decorrentes dos resultados da pesquisa in vitro.

Os dentes removidos foram doados para o trabalho de pesquisa, pois não há na FOL um banco de dentes.

O recrutamento foi executado pelo bolsista do curso, segundo a indicação do curso de Especialização em Ortodontia, sob a supervisão do orientador. Para a extração dos dentes e a utilização destes nesta pesquisa, utilizou-se um termo de consentimento livre e esclarecido dos responsáveis pelo adolescente, obtido pelo bolsista na disciplina de cirurgia, sob rigorosa supervisão do orientador quanto ao item de segurança e confiabilidade. Posteriormente, os termos de consentimento foram arquivados na FOL pelo orientador. Este trabalho foi aprovado pelo Comitê de Ética em Pesquisa (CEP) - UNIMEP, em 3/5/05 - Prot. no 26/05.

Após a extração, os dentes foram recolhidos pelo bolsista e armazenados em solução de formalina a $10 \%$ por 72 horas, passando-se, então, a uma armazenagem posterior em água destilada até o momento do uso. Após a coleta, que se processou semanalmente, os dentes foram limpos por raspagem e fixados por mais 72 horas na mesma solução, evitando, assim, possível decomposição do tecido pulpar, passando-se, então, a uma armazenagem posterior em água destilada até o momento de uso. Todos os dentes foram examinados com lupa com aumento de 10x, descartando-se aqueles que apresentavam pequenas trincas, anomalias de esmalte dentário, abrasão, dentes de coloração amarelada intensa e com hipercementose. Ao todo, foram selecionados 40 pré-molares livres de cáries. Os dentes foram limpos com pedra-pomes e água com taça de borracha e lavados abundantemente com água para, então, serem realizadas cavidades padronizadas tipo classe $\mathrm{V}$ na vestibular e lingual de cada dente, totalizando 80 cavidades, segundo Barnes et al. ${ }^{21}$. Elas foram iniciadas com uma ponta diamantada número 1015 até alcançar um diâmetro de $3 \mathrm{~mm}$. A seguir, com uma broca carbide número 245, aprofundava-se a cavidade até atingir 1,5 mm. Ambas, ponta diamantada e broca carbide, foram utilizadas em alta rotação e refrigeradas com spray ar-água 
e com um cursor para mensuração da profundidade, sendo que, a cada cinco preparos cavitários, elas foram substituídas. O acabamento das paredes foi executado com a mesma broca carbide em baixa rotação e recortadores de margem gengival. As cavidades tipo classe $\mathrm{V}$ foram preparadas com a parede oclusal em esmalte dentário, e a parede gengival, em cemento dentário. As características finais das cavidades foram: parede axial convexa em todos os sentidos; paredes circundantes ligeiramente expulsivas formando ângulo reto com a superfície externa do dente; ângulos internos arredondados; ângulo cavosuperficial nítido e sem bisel e ausência de retenções adicionais. Os 40 dentes com as cavidades preparadas foram divididos em quatro grupos de dez para serem restaurados com os materiais a serem testados:

- Grupo I (controle) - sem condicionamento ácido e restaurações com a resina composta micro-híbrida Z-250 $3 \mathrm{M}$. Após o preparo cavitário, o esmalte e a dentina foram lavados, abundantemente, por 30 segundos com água e não foram condicionados com ácido fosfórico. Foi removido o excesso de água com jatos de ar no esmalte, enquanto que na dentina foi utilizado o papel absorvente, deixando a dentina úmida. Foi aplicada a resina composta Z-250 em camadas oblíquas, primeiramente na cervical/axial, seguido da oclusal/ axial e, finalmente, na vestibular, com uma espátula de titânio e fotopolimerizada por 40 segundos cada camada com o aparelho Fotopolimerizador DB-686 (Dabi Atlante).

- Grupo II - sistema da resina composta micropartícula Silux Plus 3M. Após o preparo cavitário e condicionamento com ácido fosfórico a 35\%, por 30 segundos, foram aplicadas duas camadas consecutivas do adesivo Scotchbond Multi Uso Plus no esmalte e dentina, seguido de secagem rápida por dois a cinco segundos com ar, e fotopolimerizado por dez segundos. A resina composta foi colocada em incrementos inferiores a 2,5 $\mathrm{mm}$ de profundidade, com espátula de titânio, sendo cada camada incremental fotopolimerizada por 40 segundos, até completar a restauração.

- Grupo III - sistema da resina composta micro-híbrida Z-250. Preparadas as cavidades, foram condicionados o esmalte e a dentina por 30 segundos e, mantendo-se a dentina úmida, foi aplicado o sistema adesivo Single Bond na cavidade, com um aplicador próprio por 30 segundos. Os excessos foram removidos com jatos de ar (três a cinco segundos) e fotopolimerizado por dez segundos. Foi aplicada uma segunda camada do mesmo material, obedecendo-se o mesmo procedimento. A resina composta foi aplicada em incrementos inferiores a 2,5 $\mathrm{mm}$, sendo cada camada fotopolimerizada por 40 segundos, até o preenchimento total da cavidade.

- Grupo IV - sistema da resina composta nanohíbrida Grandio Voco. Após o preparo cavitário e condicionamento com ácido fosfórico a 35\% por 30 segundos, foram aplicadas duas camadas consecutivas do adesivo Admira Bond no esmalte e dentina, seguido de secagem rápida por dois a cinco segundos com ar, e fotopolimerizado por dez segundos. A resina composta foi colocada em incrementos inferiores a 2,5 $\mathrm{mm}$ de profundidade, com espátula de titânio, sendo cada camada incremental fotopolimerizada por 40 segundos, até completar a restauração.

Concluídas as restaurações de todos os grupos, o acabamento destas constituiu-se na remoção dos excessos grosseiros com lâmina de bisturi número 15. Os dentes, assim preparados, foram imersos em água destilada por 24 horas, em estufa por $37^{\circ} \mathrm{C}$. Decorrido esse tempo, foram realizados 
o acabamento e polimento das restaurações com discos Sof-lex sequenciais. Os dentes foram então totalmente impermeabilizados com duas camadas de Araldite de presa rápida e duas de esmalte para unhas, em cores diferentes para cada grupo, preservando-se $2 \mathrm{~mm}$ ao redor das restaurações sem a impermeabilização. Após o período de secagem (aproximadamente uma hora), os dentes foram submetidos à ciclagem térmica.

A ciclagem térmica utilizou temperaturas de $5^{\circ} \mathrm{C}$ e $55^{\circ} \mathrm{C}$ com um total de cem ciclos, de 30 segundos para cada um dos extremos de temperatura. Para realizar a ciclagem, os dentes foram colocados no corante azul de metileno a $2 \%$ e assim mantidos durante a sequência de ciclos realizados. Para o controle das temperaturas necessárias, foram utilizados termômetros próprios. Completados os ciclos, os dentes foram mantidos em azul de metileno a $2 \%$ por 24 horas a $37^{\circ} \mathrm{C}$.

Concluída a ciclagem térmica, os espécimes foram lavados, escovados e mantidos em água corrente por duas horas e por igual tempo em condição ambiente para secagem natural. Uma vez secos os dentes, a película impermeabilizante foi removida deles por raspagem e estes foram fixados em uma placa de madeira por meio de godiva. Os dentes foram então seccionados ao meio no sentido vestíbulo lingual, longitudinalmente, com um disco diamantado fixado em um micrótomo próprio, sob refrigeração à água. $\mathrm{O}$ excesso de água foi removido colocando-se os dentes seccionados em papel absorvente por 30 minutos. A avaliação da infiltração marginal foi realizada por três examinadores calibrados entre si, com uma lupa com aumento de $10 x$ e classificada segundo o grau de penetração do corante. Em consenso, os examinadores, por análise prévia, escolheram somente uma das secções, ou seja, a que obteve maior grau de penetração do corante.
Para esse processo, seguimos a metodologia usada por Nunes OBC et al. ${ }^{22}$.

O grau de infiltração foi atribuído segundo o critério de escores modificados por Crim e Garcia-Godoy: ${ }^{23}$

0 - Nenhuma infiltração

1 - Infiltração até a metade da parede circundante

2 - Infiltração em toda a parede circundante

3 - Infiltração na parede circundante e axial

4 - Infiltração na parede circundante, axial e em direção à polpa.

Os dados obtidos foram organizados e submetidos à análise estatística por meio do teste não paramétrico de Kruskal-Wallis.

\section{Resultados e Discussão}

Foram utilizados 40 dentes prémolares livres de cáries nos quais foram realizadas cavidades padronizadas tipo classe $\mathrm{V}$, na vestibular e lingual de cada dente, totalizando 80. As cavidades preparadas foram divididas em quatro grupos de dez dentes. Concluídos os procedimentos descritos em materiais e métodos, como a ciclagem térmica e colocação no corante, os dentes foram cortados longitudinalmente no sentido vestíbulo-lingual, para análise do grau de infiltração produzido.

A avaliação da infiltração marginal foi realizada por três examinadores calibrados entre si, com uma lupa com aumento de $10 \mathrm{x}$ e classificadas segundo o grau de penetração do corante em escores de 0 a 4. Em consenso, os examinadores por análise prévia, escolheram somente uma das secções, ou seja, a que obteve maior grau de penetração do corante.

A Tabela 1 apresenta os resultados obtidos por intermédio de escores médios. Para a comparação entre os grupos foi utilizado o teste de Kruskal-Wallis; quando este mostrou diferença estatisticamente significante foi utilizado o teste de Dunn para comparações múltiplas. 


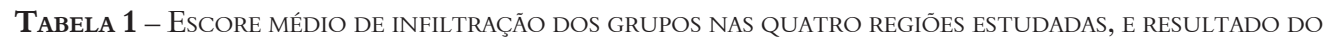
TESTE DE KRUSKal-Wallis

\begin{tabular}{ccccc}
\hline Grupo & $\begin{array}{c}\text { Esmalte } \\
\text { Vestibular }\end{array}$ & $\begin{array}{c}\text { Esmalte } \\
\text { Lingual }\end{array}$ & $\begin{array}{c}\text { Cemento } \\
\text { Vestibular }\end{array}$ & $\begin{array}{c}\text { Cemento } \\
\text { Lingual }\end{array}$ \\
\hline I & $4,0^{\mathrm{a}}$ & $4,0^{\mathrm{a}}$ & $4,0^{\mathrm{a}}$ & $4,0^{\mathrm{a}}$ \\
II & $1,7^{\mathrm{b}}$ & $1,6^{\mathrm{b}}$ & $2,3^{\mathrm{ab}}$ & $1,7^{\mathrm{b}}$ \\
III & $1,4^{\mathrm{b}}$ & $1,3^{\mathrm{b}}$ & $1,8^{\mathrm{ab}}$ & $1,7^{\mathrm{b}}$ \\
IV & $1,3^{\mathrm{b}}$ & $1,1^{\mathrm{b}}$ & $1,6^{\mathrm{b}}$ & $1,5^{\mathrm{b}}$ \\
\hline
\end{tabular}

Dentro de cada grupo, regiões com a mesma letra não

possuem diferença estatisticamente significante entre si.

Para a comparação entre as regiões de um mesmo grupo foi utilizado o teste de Friedman; quando este mostrou diferença estatisticamente significante, aplicou-se o teste de Dunn para comparações múltiplas.

Em todos os testes estatísticos foi adotado nível de significância de 5\%. Assim, obteve-se os seguintes resultados grupo a grupo:

- Grupo I (controle) - sem condicionamento ácido e sem sistema adesivo e restaurações com resina composta micro-híbrida Z 250 - 3M. Foi o grupo que obteve os maiores escores de infiltração marginal, tanto em esmalte quanto em cemento, sendo estatisticamente significante com relação aos grupos II, III e IV, com exceção do cemento vestibular dos grupos II e III (Tabela 1).

- Grupo II - sistema de resina composta micropartícula Silux Plus $3 \mathrm{M}$, condicionamento com ácido fosfórico a 35\% e aplicadas duas camadas consecutivas de adesivo no esmalte e na dentina; a resina foi aplicada em incrementos inferiores a $2,5 \mathrm{~mm}$. Os escores de infiltração marginal não foram estatisticamente significantes entre esmalte e cemento e entre os grupos III e IV, mas foram significantes em relação ao grupo I, com exceção do cemento vestibular (Tabela 1).

- Grupo III - sistema de resina composta microhíbrida Z 250 - 3M, condicionamento com ácido fosfórico a $35 \%$ e aplicadas duas camadas consecutivas de adesivo no esmalte e dentina e na dentina; a resina foi aplicada em incrementos inferiores a $2,5 \mathrm{~mm}$. Os escores de infiltração marginal não foram estatisticamente significantes entre esmalte e cemento, nem entre os grupos II e IV, mas foram significantes em relação ao grupo I, com exceção do cemento vestibular (Tabela 1).

- Grupo IV - sistema de resina composta nanohíbrida Grandio VOCO, condicionamento com ácido fosfórico a $35 \%$ e aplicadas duas camadas consecutivas de adesivo no esmalte e na dentina; a resina foi aplicada em incrementos inferiores a $2,5 \mathrm{~mm}$. Foi o grupo que obteve numericamente os menores escores de infiltração marginal, mas não foram estatisticamente significantes entre o esmalte e cemento e entre os grupos II e III, mas foi significante em relação ao grupo I (Tabela 1).

O Gráfico 1 expressa valores médios de infiltração marginal dos quatro grupos, nas quatro regiões estudadas.

Gráfico 1 - ESCORE MÉDio PARA CADA GRUPO NAS QUATRO REGIÕES ESTUDADAS.

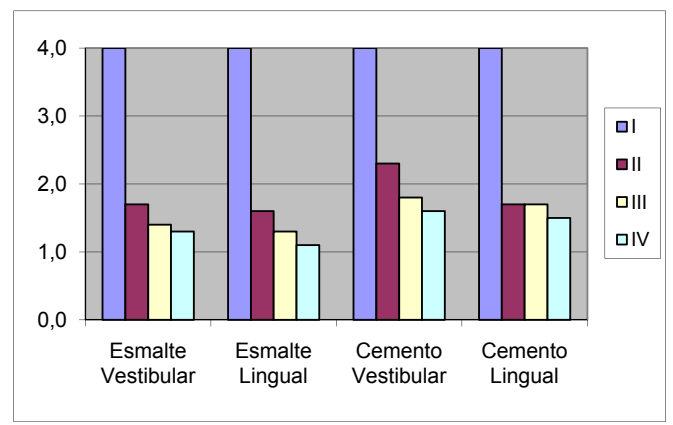


A infiltração marginal é uma das principais deficiências apresentadas pelas restaurações executadas com resina composta. ${ }^{11,12,13,20,24}$ Essa infiltração ocorre principalmente pela deficiente adaptação do material restaurador à estrutura dentária.14 Pesquisas mostram que a contração de polimerização, influenciada pelo tamanho das partículas inorgânicas, é um fator preponderante no selamento marginal $7,8,9,12,13,14.20,22$ Até o presente, não se dispõe de resinas compostas livres de contração de polimerização e com coeficiente de expansão térmica semelhante ao dos tecidos dentários, o que permitiria a confecção de restaurações perfeitamente seladas e adaptadas.

Pode-se observar que, nos últimos anos, houve uma grande preocupação por parte dos fabricantes de materiais odontológicos em desenvolver uma resina composta que apresentasse uma contração de polimerização reduzida. Com o advento da nanotecnologia ou novos materiais como o Ormocer, nasce uma nova geração de resinas compostas que incluem em sua carga inorgânica partículas nanohíbridas, conferindolhes uma menor contração de polimerização. Isso poderia sugerir um comportamento clínico melhor da restauração, sobretudo no que respeita à formação de fendas marginais e seu potencial de microinfiltração. ${ }^{20}$

Certamente, as resinas compostas do século XXI terão padrões fisiológicos comparados ao esmalte e à dentina. Provavelmente, as resinas de escolha serão de partículas ultrafinas para todas as finalidades. A fim de analisar a aplicação dessas resinas, seria importante para os clínicos, pesquisadores e fabricantes que fosse desenvolvido um método laboratorial de avaliação, confiável e de execução rápida mesmo que complexa. Logicamente, estudos clínicos de longo tempo devem ser efetuados para confirmação dos resultados obtidos anteriormente em testes laboratoriais.
Todas as resinas compostas testadas apresentaram infiltração marginal, porém em graus variáveis, apesar do condicionamento ácido aliado ao uso da técnica da dentina úmida, da técnica incremental para inserção da resina composta, a fim de reduzir o fator $\mathrm{C}$, o acabamento e o polimento após 24 horas.

Pode-se perceber que fatores inerentes ao material, à configuração cavitária, à técnica restauradora e à técnica de polimerização têm influência significativa nos efeitos da contração de polimerização, bem como na qualidade do selamento marginal de restaurações de resina composta. Dentre esses fatores, alguns como a seleção da resina composta/sistema adesivo (considerando sua composição, matriz), a configuração cavitária e a técnica restauradora (associação de materiais, técnica de inserção, modulação da fotoativação) podem ser, de certa forma, controlados pelo cirurgião-dentista, reduzindo os efeitos de contração, melhorando, portanto, a qualidade marginal de restaurações realizadas com resinas compostas fotoativadas. ${ }^{25}$ Entretanto, não se deve ter a ilusão que a análise de uma propriedade isolada seja suficiente para confirmar a boa qualidade ou o desempenho clínico do produto. É necessário agrupar todas as propriedades e avaliá-las, em conjunto, para se ter uma afirmação das resinas compostas que apresentam o melhor comportamento clínico.

\section{Conclusão}

1. Das resinas compostas testadas, nenhuma delas foi capaz de impedir a infiltração marginal do corante tanto em esmalte quanto em cemento.

2. Não houve diferença estatisticamente significante entre as paredes oclusal em esmalte e gengival em cemento e as faces vestibular e lingual.

3. As resinas compostas de micropartículas, microhíbridas e nanohíbridas não mostraram diferença estatisticamente 
significante entre si, apesar da resina nanohíbrida Grandio - VOCO ter apresentado os menores escores de infiltração marginal.

4. Houve diferença estatística significante entre o grupo I (controle) e os grupos II, III e IV, com exceção dos grupos II e III no que tange ao cemento vestibular.

\section{REFERÊNCIAS BIBLIOGRÁfICAS}

1. Buonocore MG. A simple method of increasing the adhesion of acrylic filling materials to enamel surfaces. J Dent Res 1955; 34: 849-853.

2. Bowen RL. Properties of silica reenforced polymer for dental restorations. J Amer Dent Ass 1963; 66(1):57-64.

3. Farias DG, Avelar RP, Bezerra ACB. Estudo comparativo da infiltração marginal em restaurações de classe $\mathrm{V}$. Pesqui Odontol Bras Jan/Mar 2002; 16(1): 83-88.

4. American Dental Association. Council on Dental Materials, Instruments and Equipment: Choosing intracoronal restorative materials. J Am Dent Assoc 1994; 125(1):102-103.

5. Leinfelder KF. et al. Resinas compostas anteriores e posteriors. The Dental Advisor (Edição em Português) Jan1994; 1(1):1-6.

6. Conceição EN. Dentística: saúde e estética. Porto Alegre: Artes Médicas Sul, 2000.

7. Bayne SC, Heymann HO, Swift Jr EJ. Up-date on dental composite restorations. J Amer Dent Ass Jun1994; 125:687-700.

8. Hinoura K, Setcos JC, Phillips RW. Cavity design and placement techniques for class 2 composites. Oper Dent 1988;13(1):12-19.

9. Hansen EK, Asmussen E. Marginal adaptation of posterior resins: Effect of dentin-bonding agent and hygroscopic expansion. Dent. Mater Mar 1989; 5(2):122-6.

10. Bausch JR. Tandheelkundige compositen II. Klinisch- MateriaalKundige Eigenschappen [thesis]. University of Amsterdam, p. 125-54, 1982.
11. Prati, C. Marginal adaptation of posterior resins. Effect of dentin-bonding agent and hygroscopic. Dent. Mater Mar 1989; 5:122-6.

12. Prati C. Early marginal microleakage in class II resin composite restorations. Dent Mater Nov 1989; 5(22):392-8.

13. Suh BI. Understanding and controlling the effect polymerization shrinkage stress in composite restorations. In: Simposio Internazionale de Odontoiaria Adesiva e Riconstrutiva, 4., S. Margherita Ligure, 2000. Atti. Italy, Probagonsti in Odontoiatria, 2000. p. 60-67.

14. Tessore G, Trinchero A. Post-operative sensitivity consequent to composite restorations in posterior sectors. In: Simposio Internazionale de Odontoiaria Adesiva e Riconstrutiva, 5., S. Margherita Ligure, 2001. Atti. Italy, Probagonsti in Odontoiatria, 2001. p. 62-65.

15. Santos MJCM, Silva e Souza Jr MH, Mondelli RFL. Novos conceitos relacionados à fotopolimerização das resinas compostas. JBD Jan-Mar 2002; 1(1):6-12.

16. Gomes JC et al. Avaliação da formação de gaps axiais utilizando um adesivo de $4^{\text {a }}$ geração e um adesivo autocondicionante, em cavidades de classe V. J Bras Dent Est Jul-Set 2002;1(3):213-218.

17. Ursi WJS, Simone JL. Contribuição ao estudo dos sistemas adesivos dentinários utilizados sob restaurações de resina composta. Ênfase em biocompatibilidade, microinfiltração marginal e resistência adesiva. Rev Inst Ciênc Saúde Jul-Dez 1999; 17(2):127-38.

18. Formolo E, Sartori A, Demarco FF. Infiltração marginal em cavidades de classe V com o uso de diferentes materiais adesivos. Rev Pos-grad Out-Dez 2001; 8(4):306-12.

19. Cavalcanti RCM. Avaliação da microinfiltração marginal de dois sistemas adesivos em cavidades preparadas com laser Er: YAG ou alta rotação. Camaragibe, 2003. Tese (Mestrado) - Faculdade de Odontologia, Universidade de Pernambuco.

20. Pereira RA. Avaliação comparativa por três métodos diferentes da contração de polimerização de resinas compostas. 
São Paulo, 2005. 110 p. Tese (Mestrado) - Faculdade de Odontologia, Universidade de São Paulo.

21. Barnes DM, McDonald NJ; Thompson VP; Blank LW; Shires PJ. Microleakage in facial and lingual class 5 composite restorations: a comparison. Oper Dent 1994; 19: 133-7.

22. Nunes OBC. Avaliação in vitro da microinfiltração marginal em cavidades classe $\mathrm{V}$, restauradas com resinas compostas condensáveis, resina composta híbrida, resina composta modificada por poliácidos e ionômero de vidro modificado por resina. Bauru, 2001. 141 p. Tese (Doutorado) - Faculdade de Odontologia de Bauru da Universidade de São Paulo.
23. Crim GA, Garcia-Godoy GF. Microleakage: the effect of storage and cycling duration. J prosth Dent 1987; 57: 574-6.

24. Souza Jr MH. Adesivos dentinários: evolução, estágio atual e considerações clínicas para sua utilização. MaxiOdonto: Dentística Jan 1995; 1 (1): 1-18.

25. Batitucci MHG, Araújo PA. Avaliação da adaptação marginal de resinas compostas em cavidades dentinárias submetidas a diferentes sistemas adesivos. Rev FOB Jan-Dez 1995; 3 (1-4): 157-162.

Recebimento do artigo: 23/1/08 Aprovado: 23/10/08 